\title{
Analysis on Problems and Countermeasures of Supply and Operation Mechanism of Public Sports Service in Shaanxi Province
}

\author{
Haiyan Zuo
}

Weinan Normal University, Weinan, Shaanxi, 714099

\author{
Keywords: Public Sports Service; Supply Mechanism; Problem Analysis
}

\begin{abstract}
With the continuous transformation of China's government functions, the construction of basic public service system has become the key content of our government's work. Public sports services are of great significance for improving the quality of the people and promoting social progress. Although the public sports service in Shaanxi Province has begun to take shape in recent years, it has promoted the construction and opening of sports venues, and the public's health awareness has also increased. However, there are still many problems in the actual public sports service supply and operation mechanism, such as low participation of sports social organizations, problems in policy supply, and financial problems. Therefore, it is necessary to strengthen research on these issues to promote the high supply mechanism of public sports services in Shaanxi Province.
\end{abstract}

\section{The Public Sports Service Supply Method}

Specifically, the supply methods of public sports services in Shaanxi Province mainly include government supply, market supply and voluntary supply:

Government supply is divided into direct and indirect ways. The government directly provides public sports services mainly by the government to fully fund investment. Usually, this model is adopted for a small number of public sports services, such as the formulation of sports laws, regulations and policies, and sports disciplines. Fundamental research, maintaining equality and continuity of services, in addition, some public sports venues, sports centers, sports museums and other infrastructure are usually provided by the government in full. However, the direct supply of public sports services by the government will cause some institutional defects, such as oversupply, misplacement, and inability to guarantee post-operations. Therefore, it is necessary to introduce the government to provide public sports services indirectly to make up for this deficiency. Indirect provision of public sports services by the government is mainly funded by the sports department, and combined with national differential appropriations and subsidies to provide public sports services to the public. For example, the national fitness path widely implemented in Shaanxi is funded by the state and purchased from enterprises. A form of construction that is open to the public free of charge.

As the name implies, market supply provides public sports services to the public through market transactions, which is also the product of market economic system reform. The government regulates public sports service behavior according to market rules and market mechanisms. In the traditional public sports service supply model, state organizations and governments are the only subjects of public sports service supply. There are problems such as information asymmetry, service bilateral monopoly, and budget maximization. Public sports services will have a "government failure" phenomenon. In this case, the market as another social operation mechanism will become an important means to solve the problem of government failure. The marketization of public sports services has broken the theoretical logic of the traditional public sports service system.

The so-called voluntary supply refers to the provision of public services to the public through voluntary contributions by individuals or groups. It provides the public sports services to the public free of charge or part of the unpaid free of charge through social donations or public welfare lottery. Voluntary supply is the third form of public sports service supply in addition to government supply and market supply. At present, the model of voluntary supply in China is not mature enough, and 
the voluntary supply model in developed countries such as Europe and the United States is more common. Its common modes of operation include non-reimbursable public welfare, voluntary services and non-profit-based charging services. Although the voluntary supply model will be limited by the scale of voluntary fundraising, its economic behavior and humanistic care are integrated, and it is independent of the other two public service supply models, so it has a very broad development prospect.

\section{The Problems Existing in the Supply Mechanism of Public Sports Services in Shaanxi Province}

The participation of Shaanxi sports social organizations in the provision of public sports services is not comprehensive enough, which is manifested in the following aspects: First, the number of sports social organizations is small, the distribution is unreasonable, and the structure is unscientific. The number of sports associations in Shaanxi Province is seriously insufficient, not only far behind the developed countries, but also has a large gap compared with the first- and second-tier cities in China, which cannot meet the basic sports public service needs of the people. Moreover, the problem of unbalanced distribution and unreasonable structure of sports social organizations is also very prominent. The sports social organizations in Shaanxi Province are mostly concentrated in urban areas, and the number of rural areas is very rare. Second, there is a lack of professionals. The staff of sports social organizations mainly includes three types: full-time, part-time and volunteer. At present, most of the sports social organizations in Shaanxi Province are part-time personnel or volunteers. The full-time staff is seriously inadequate, and the government and institutional units account for the full-time staff. The proportion is high and cannot guarantee its specialization and professionalism. Finally, the funding for the event and the office space are seriously inadequate. At present, more than 60\% of sports associations in Shaanxi Province have serious shortages of funds for sports associations. It is difficult for unregistered sports social organizations to obtain government funding, such as comprehensive fitness activities sites; at least half of sports organizations cannot separately account for three points. One of the sports clubs does not even have an office space. It can be seen that the problem of low participation of sports social organizations in the public sports service supply mechanism in Shaanxi Province is very prominent.

At present, China has formed a clear framework for the supply of sports public services. However, there is still a lack of scientific and complete laws and regulations and policy planning in Shaanxi Province. For example, some sports fields still lack the norms of laws and regulations, even if there are operational regulations. In the form of circulation, the system is inefficient. With the continuous development of sports in China, the relevant state departments and government departments have made a comprehensive definition of the work objectives, division of duties, and safeguard measures for sports public services. However, when they are implemented in local governments, they are not combined with local conditions. It is not possible to guide local practices. In Shaanxi Province, government departments and sports functional departments rarely formulate operational policies with the actual development of sports in the region. The performance evaluation and incentive mechanism of public sports needs to be improved, and there is a lack of a clear and decisive performance evaluation. In addition, the fiscal and taxation policies of Shaanxi Province are not compatible with the development of sports public services. The allocation of basic sports public service responsibilities is unreasonable and cannot meet the funding needs of sports public services.

To a certain extent, capital is the main bottleneck in the development of sports public services in Shaanxi Province, mainly in the following aspects: First, the public finance investment is insufficient. Among the various administrative departments, the sports administrative department has a weaker status, and the resources available for control are also very limited. The construction fund of the sports public service supply system in Shaanxi Province is still based on the overall macro distribution of the State Sports General Administration, plus central transfer payments. The funds have caused the Shaanxi public service system to be out of touch with the overall national policy. In addition, the lack of social capital intervention is another cause of insufficient supply of 
funds in Shaanxi. The impact of the issue of receptor system, sports social organizations, enterprises, and individual capital are difficult to smoothly intervene in the field of sports public services, coupled with the absence, offside and misplacement of the government. In the end, the problem of insufficient supply of sports public service funds has become increasingly prominent.

\section{The Strategy to Improve the Effectiveness of the Public Sports Service Supply Mechanism in Shaanxi}

In view of the above problems in the supply of public sports services in Shaanxi, it is suggested to improve from the following aspects:

The main forms of government purchase of public sports services include contract outsourcing, public-private partnership, and voucher system. There are two kinds of purchase methods for contract outsourcing, namely, competitive purchase and non-competitive purchase. The competitive purchase is determined by the government department after public sports purchase target, and then the public bidding is carried out, and the bidding standard of "low price and high quality" is adopted to achieve the reduction. The government purchases costs and improves the quality of public sports services; non-competitive purchases are mainly signed by government departments and service entities, and the two parties jointly study the contents and service methods of the contracts. Contract outsourcing can reduce the government's investment risk and improve the quality and efficiency of government public sports services. Public-private partnerships are mainly provided by the government, the market and third parties to provide public sports service models. This is the approach adopted by some large stadiums in China. Under the public-private partnership model, the government does not need to directly contribute capital, but only allows private enterprises to participate in public sports services through franchising and public bidding. The voucher system refers to the government issuing public sports service vouchers to the public. The government purchases free or low-cost open consumer service vouchers from sports organizations, and then issues free service vouchers to the public to encourage more people to participate in sports activities. . Shaanxi Province can learn from the above three forms of government purchasing public sports services, or a single application, or comprehensive application, to improve the efficiency and effectiveness of public sports services.

The public sports service supply mechanism in Shaanxi Province adopts the form of multi-center subject supervision, which not only can guarantee the quality of service, but also enrich the form of public sports service and improve its applicability. The supervision of multi-center subjects includes governments at all levels, people, social organizations and mass media. Wait. In the multi-center subject supervision mode, we must first abolish the decision-making error exemption system to make the public sports service project decision-making process more transparent; establish a sound basic public sports service supply performance evaluation system to improve the efficiency of the functional department. Secondly, strengthen the propaganda of national sports laws and regulations, publicize the rights and obligations they should enjoy, and raise the awareness of the public's supervisory subjects to promote the enthusiasm of the people to participate in decision-making and make their opinions more reasonable. Finally, improve the transparency of the supply of public sports services. In the process of public affairs supervision, the advantages of various media in the dissemination of information are irreplaceable. Therefore, in the supervision system of public sports service supply multi-center subjects, it is necessary to establish an Internet, telephone hotline, newspapers and magazines, radio and television, etc. A kind of information supervision network combined with channels to improve the information construction of public sports services. In addition, it is necessary to strengthen the management of mass sports organizations and sports teams to improve the self-organization and self-management capabilities of spontaneous sports groups, so that they can give full play to the feedback, evaluation and supervision functions of public sports service supply.

First, to increase the total amount of capital supply, governments at all levels in Shaanxi Province should continue to increase investment in sports public service funds, increase the coverage of government budgets, and achieve mutual matching of financial resources and 
responsibilities. The public bidding method is used to legally determine the bidders for the construction of sports facilities, so as to reduce the construction risks of the government and reduce the pressure on the government's fiscal expenditure. Second, further optimize the funding structure. Optimize the structure of fiscal expenditure, reduce the scale of sports expenditures; increase the proportion of capital investment in sports public service organization construction, policy research and scientific research guidance. Finally, to narrow the imbalance between regional and urban and rural capital supply, Shaanxi Province should establish a stable fund transfer payment system for economically underdeveloped counties and township governments to ensure that payment funds can be directly implemented in economically underdeveloped regions and rural areas.

\section{Conclusion}

In short, in the development of sports in Shaanxi Province, the public sports service supply mechanism is an important issue that all levels of government need to face. Although the sports industry in Shaanxi Province has made great progress in recent years, the ability and quality of public sports service supply has also been greatly improved, but the public's demand for public sports is also increasing, the supply is insufficient, the quality is not high, and there is no supervision. The problem still exists, so it is of great practical significance to construct a perfect public sports service supply mechanism. Government departments should actively change service functions, strengthen the practice of public sports services, adopt the government's method of purchasing public sports services, and implement a multi-center subject supervision model.

\section{References}

[1] Yang Hua, Wang Kaizhen, Xiong Xiaozheng, et al. Development and thinking of mass sports in China since the reform and opening up [J]. Journal of Beijing Sport University, 2015, 28(6): 721726.

[2] Xiao Linpeng, Li Zonghao, Yang Xiaochen. The Concept of Public Sports Service and Its Theoretical Analysis [J]. Journal of Tianjin Institute of Physical Education, 2017, 22(2): 97-101.

[3]Yu Jian, Li Wanlai, Liu Qing. The definition of social public sports service and the study of transforming government functions [J]. Sports Science, 2015, (11): 3- 10.

[4]LIU Yanli, YAO Congrong. On the Diversification of Production Subjects in China's Sports Public Service Industry from the Perspective of Economics [J]. Journal of Xi'an Institute of Physical Education, 2014, 21(5): 16- 18.

[5]XIAO Lin-peng, LI Zong-hao, YANG Xiao-chen. Conceptual Development and Structure of Public Sports Service System in China [J]. Journal of Tianjin Institute of Physical Education, 2017, 22(6): 472- 475. 